\title{
Device Closure of Atrial Septal Defect
}

\section{- Immediate and Mid-Term Results -}

\author{
Hideaki Ueda, MD; Sadamitsu Yanagi, MD, PhD; Hideaki Nakamura, MD; \\ Kentarou Ueno, MD, PhD; Ryouhei Gatayama, MD; \\ Toshihide Asou, MD, PhD; Seiyo Yasui, MD
}

\begin{abstract}
Background: Transcatheter closure of atrial septal defects (ASDs) has become an alternative to open surgical procedures. The Amplatzer septal occluder (ASO) has been approved since 2005 in Japan, but there are still many concerns about adverse events, and information about outcomes and complications is limited. The objective of this study was to assess the immediate and mid-term outcomes of device closure of secundum ASDs.
\end{abstract}

Methods and Results: From August 2005 to July 2011, 208 consecutive patients with a significant secundum ASD underwent percutaneous closure with the ASO [72 males, 136 females; median age, 7.3 years (range, 3.3-21.9 years)]. Follow-up was available for 206 (99\%) patients. Device closure was successful in 203 (98\%) patients. Device embolization occurred in 1 case within $1 \mathrm{~h}$ of device implantation, but the device was surgically retrieved without any neurological sequelae. During the follow-up period, complete closure was observed in 202 of 203 patients. There were no cases of erosions, late embolization, thrombus formation, or death.

Conclusions: Transcatheter closure of ASDs using the ASO is safe and effective, with excellent results during mid-term follow-up. Appropriate patient selection and accurate device selection is mandatory to avoid serious complications. (Circ J 2012; 76: 1229-1234)

Key Words: Amplatzer septal occluder; Atrial septal defect; Catheter interventions; Complications; Follow-up

D evice closure of secundum atrial septal defect (ASD) has become an established therapy in selected patients, including children, adolescents, and adults. The Amplatzer septal occluder (ASO; AGA Medical Corp, Golden Valley, MN, USA) is the most commonly used device for percutaneous closure of ASD. ${ }^{1-4}$ Immediate and mid-term studies have reported favorable results, but acute complications such as device migration, thromboembolic events, and erosion have occurred..$^{5-11}$

Since 2005, 2,800 ASO have been implanted to close secundum ASD in Japan. Efforts to avoid the most serious complication, erosion, have included educational programs, careful observation and measurement of defects by transesophageal echocardiography (TEE), and evaluation of configuration changes in the ascending aorta and both atrial walls after device deployment. ${ }^{5}$ Accordingly, 5 cases of erosion and 7 of device embolization have been reported up until September 2011 in Japan.

We herein present the immediate and mid-term results of transcatheter closure of ASD with the ASO device at Kanagawa Children's Medical Center.

\begin{abstract}
Methods
Patients

Between August 2005 and July 2011, 208 consecutive patients with significant secundum ASD underwent percutaneous closure [72 males, 136 females; median age, 7.3 years (range, $3.3-21.9$ years) and median body weight of $21 \mathrm{~kg}$ (range, $13-91 \mathrm{~kg}$ )]. Three patients had multiple defects and received 2 devices. The mean follow-up was 2.5 years. Patient characteristics and procedure-related data are listed in Table 1.

Indications for closure were a significant left-to-right shunt, pulmonary and systemic blood flow (Qp/Qs) ratio $>1.5$, volume overload of the right ventricle on transthoracic echocardiography, and development of symptoms. ASD assessment was performed using transthoracic echocardiography and/or TEE. Patient selection was based on the morphology and location of the defect and presence of rims around the defect. Patients with more than 2 rim deficiencies were excluded.
\end{abstract}

\section{Procedure and Device}

Defects were measured with multiplane TEE in all patients in

Received November 28, 2011; revised manuscript received December 30, 2011; accepted January 11, 2012; released online February 16, 2012 Time for primary review: 8 days

Department of Cardiology (H.U., S.Y., H.N., K.U., R.G., S.Y.), Department of Cardiovascular Surgery (T.A.), Kanagawa Children's Medical Center, Yokohama, Japan

Mailing address: Hideaki Ueda, MD, Department of Cardiology, Kanagawa Children's Medical Center, 2-138-4 Mutsukawa, Minami-ku, Yokohama 232-8555, Japan. E-mail: hidueda@gmail.com

ISSN-1346-9843 doi:10.1253/circj.CJ-11-1379

All rights are reserved to the Japanese Circulation Society. For permissions, please e-mail: cj@j-circ.or.jp 


\begin{tabular}{|lc|}
\hline $\begin{array}{l}\text { Table 1. Baseline Characteristics of Patients With Secundum } \\
\text { Atrial Septal Defect }\end{array}$ \\
$\mathrm{n}$ & 208 \\
Age, years & $8.3 \pm 3.8$ (median, 7.3) \\
Body weight, $\mathrm{kg}$ & $27 \pm 14$ (median, 22) \\
No. of female patients (\%) & $136 / 208(65 \%)$ \\
Primary ASD size, $\mathrm{mm}$ & $12 \pm 3.7(11)$ \\
TEE-based balloon sizing, $\mathrm{mm}$ & $15 \pm 4.2(14)$ \\
Size of ASO devices used, $\mathrm{mm}$ & $15 \pm 4.3(14)$ \\
Qp/Qs & $2.0 \pm 0.59(1.9)$ \\
Follow-up duration, days & $565 \pm 282(550)$ \\
\hline
\end{tabular}

Values are mean \pm SD (median) unless otherwise shown.

ASD, atrial septal defect; TEE, transesophageal echocardiography; ASO, Amplatzer septal occluder.

\begin{tabular}{|lc|}
\hline \multicolumn{2}{|c|}{ Table 2. Morphology of the Atrial Septal Defects } \\
Morphology & $\mathbf{n}(\%)$ \\
Defect with sufficient rim & $84 / 208(63)$ \\
Deficient aortic rim & $67 / 208(32)$ \\
Deficient SVC rim & $1 / 208(0.48)$ \\
Deficient IVC rim & $1 / 208(0.48)$ \\
Deficient atrioventricular rim & $0 / 208$ \\
Deficient posterior rim & $3 / 208(1.4)$ \\
Deficient posterior and IVC rims & $2 / 208(0.96)$ \\
Multiple defects & $3 / 208(1.4)$ \\
Total & 208 \\
\hline
\end{tabular}

SVC, superior vena cava; IVC, inferior vena cava.
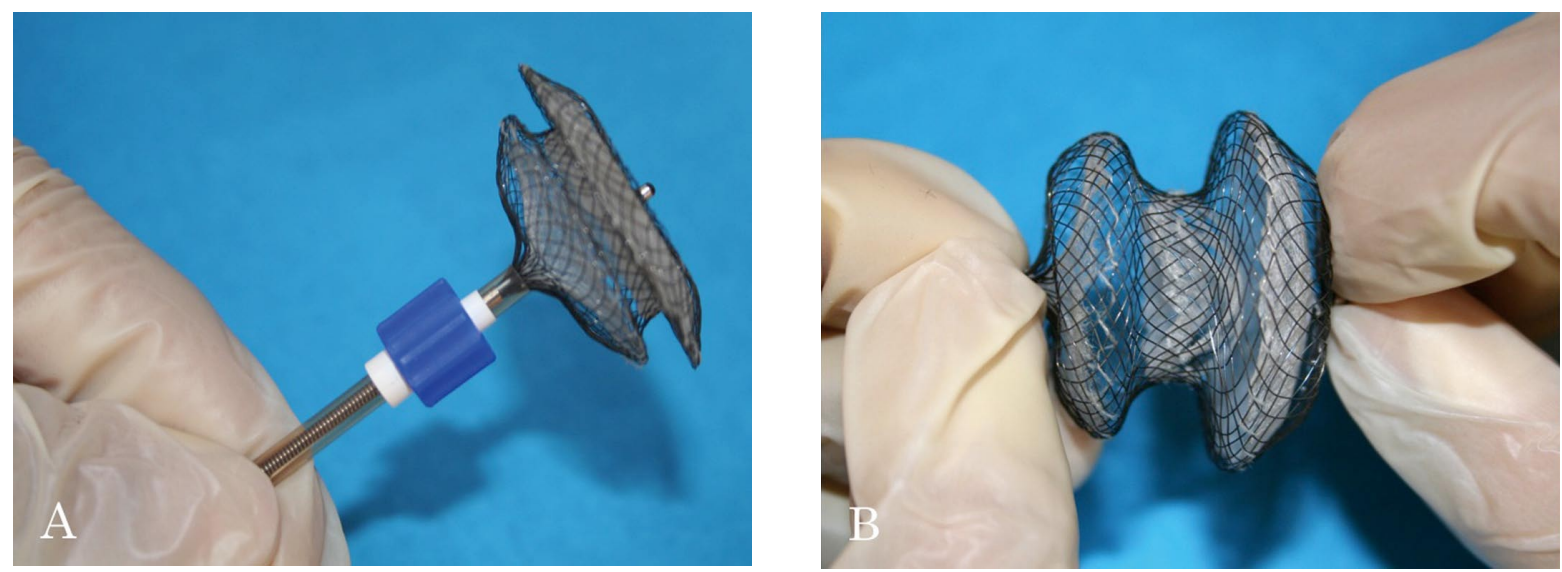

Figure 1. (A) The Amplatzer septal occluder device attached to the delivery cable. The discs are nitinol wire mesh made from an alloy of titanium and nickel. The left atrial disc is slightly bigger than the right atrial disc. (B) Lateral view of the Amplatzer septal occluder. There is polyester fabric sewn over both atrial discs to enhance thrombogenicity. The device is easily stretchable because of the characteristics of nitinol.

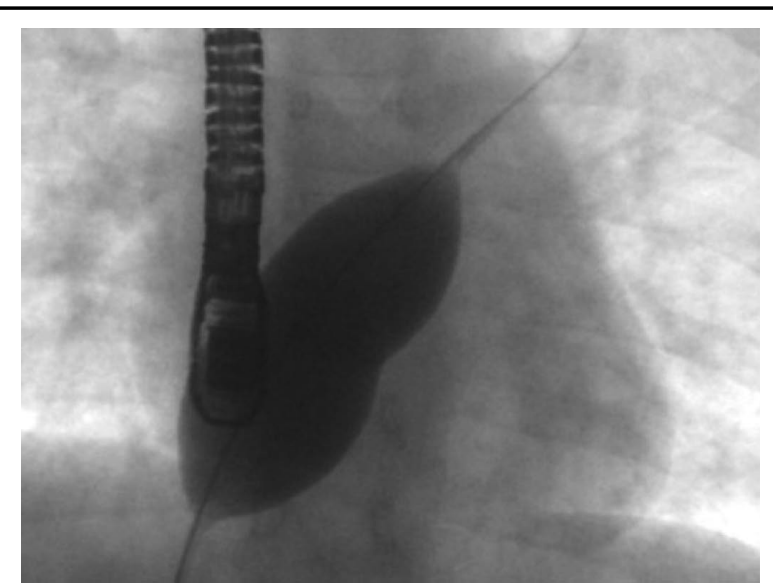

Figure 2. Cine-angiographic image of balloon sizing of an atrial septal defect (ASD). The balloon was inflated until ASD shunting was eliminated, confirmed by transesophageal echocardiography. There is a waist in the balloon indicating the diameter of the ASD. the catheter laboratory. Real-time 3-dimensional TEE was performed to describe defect morphology. ${ }^{12}$ Descriptive terms included superior, aortic, posterior, and inferior rims (Table 2). A $7 F$ sheath was inserted into the right femoral vein, and heparin $(100 \mathrm{IU} / \mathrm{kg})$ was administered. We used only the ASO (Figure 1).

\section{Sizing Balloon and Implantation Technique}

A 24- or 34-mm sizing balloon (AGA Medical Corp) was used to measure the diameter of the defect (Figure 2). To avoid oversizing with respect to avoiding erosion, the stop-flow method was used for measurement in every patient. ${ }^{13}$ Deployment of the device was performed by an approach from either the left upper pulmonary vein or right pulmonary vein. A Hausdorff sheath was used in 14 cases of relatively large defects compared with body size. ${ }^{14}$ The pigtail-assisted technique was used in 3 cases. $^{15}$ After deployment of the device, the geometry of the device and the presence of residual shunt were evaluated. The configuration of the tissue adjacent to the device, including the ascending aorta (Figure 3), atrioventricular valves, pulmonary vein, superior vena cava, inferior vena cava, and coronary sinus, was observed. Before releasing the device, a gentle "Minnesota wiggle" was performed to 


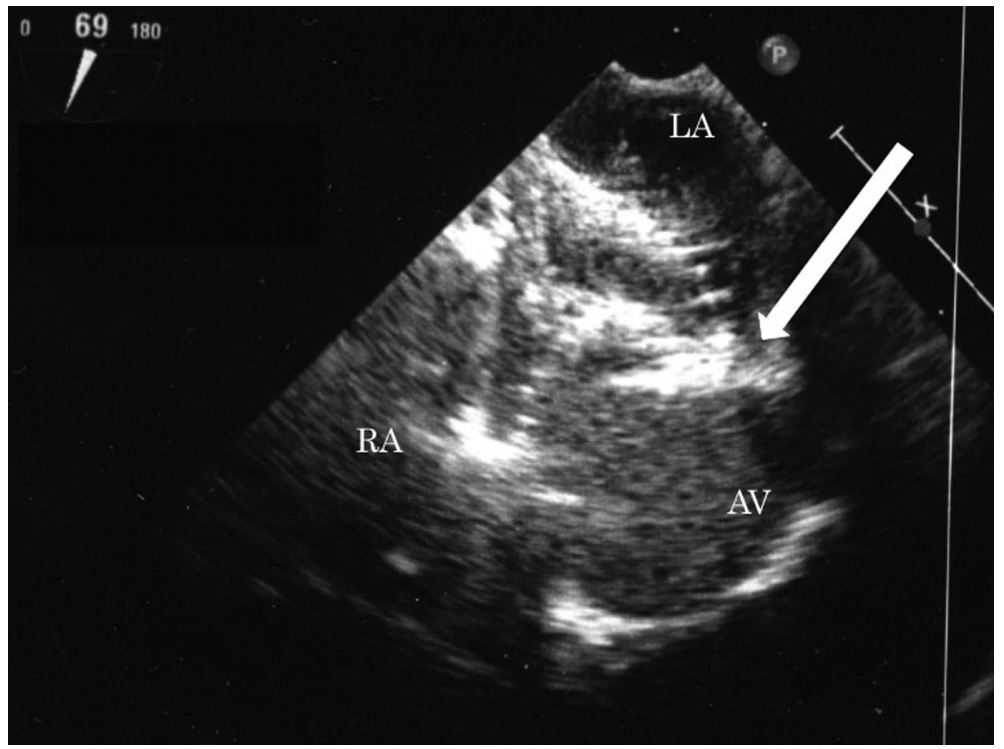

Figure 3. Transesophageal echocardiography (transducer plane angle, 69 ${ }^{\circ}$ ) demonstrating the Amplatzer occluder device slightly touching but not impinging on the aortic root (arrow). LA, left atrium; RA, right atrium; $\mathrm{AV}$, aortic valve.

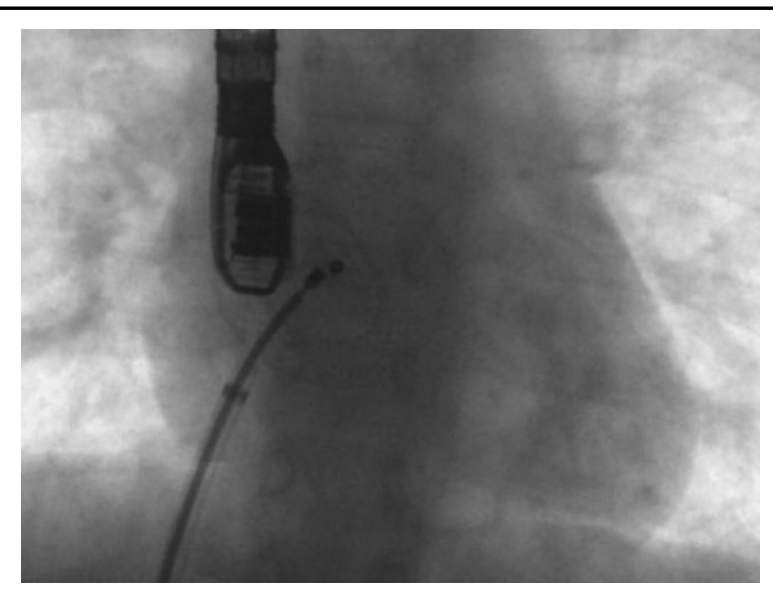

Figure 4. Cine-angiographic image of 26-mm Amplatzer septal occluder attached to the delivery cable during the "Minnesota wiggle".

\begin{tabular}{|lc|}
\hline \multicolumn{2}{|c|}{ Table 3. Complications of Device Closure of Atrial Septal Defect } \\
Major complications & $\mathbf{n ~ ( \% )}$ \\
Embolization & $1 / 208(0.48)$ \\
Erosion & $0 / 208$ \\
Advanced AV block & $0 / 208$ \\
Atrial flutter & $0 / 208$ \\
Thrombus formation & $0 / 208$ \\
Residual neurological sequelae & $0 / 208$ \\
Infective endocarditis & $0 / 208$ \\
Death & $0 / 208$ \\
Minor complications & \\
Pericardial effusion & $0 / 208$ \\
Aortic regurgitation & $0 / 208$ \\
Supraventricular tachycardia & $0 / 208$ \\
Residual leakage $(>2 \mathrm{~mm})$ & $0 / 208$ \\
Blood transfusion & $0 / 208$ \\
Transient arrhythmia & $0 / 208$ \\
Migraine & $16 / 208(7.7)$ \\
\hline
\end{tabular}

$\mathrm{AV}$, atrioventricular.

\section{Results}

of rim deficit or length $<2 \mathrm{~mm} .{ }^{16}$ Final examination by TEE was performed to verify the device location and any residual shunting.

The patients received aspirin $\left(5 \mathrm{mg} \cdot \mathrm{kg}^{-1} \cdot \mathrm{day}^{-1}\right)$ for 6 months. Before discharge, a chest X-ray, electrocardiography, and echocardiography were performed.

\section{Follow-up}

Follow-up clinical examinations, including a chest X-ray, electrocardiography, and echocardiography, were performed at 1, 2, 3, 6, and 12 months and annually thereafter. The patients were advised to take antibiotic prophylaxis for 6 months. Ticlopidine was added when migraines were occurring frequently, after routine examination of head computed tomography or magnetic resonance imaging had been completed. ${ }^{17,18}$
The device was implanted successfully in 203 (98\%) of 208 procedures. There were 3 cases of failed deployment of the device in the appropriate position. Despite repeated attempts using different techniques, the left-sided disk would not spread out, because it became lodged in the limited space of the left atrium compared with the diameter of the disk.

Device embolization occurred within a few hours after release of the device in 1 patient. A posterior rim was not detected; only a floppy inferior rim measuring $3 \mathrm{~mm}$ was observed. The diameter of the defect as measured by the sizing balloon was $23.8 \mathrm{~mm}$; consequently, a $24-\mathrm{mm}$ device was implanted for a 22-mm-diameter defect. The "Minnesota wiggle" was not performed aggressively. The implanted device had migrated into the right ventricle before the patient left the 


\begin{tabular}{lccccc|}
\hline \multirow{7}{*}{ Table 4. Follow-up Data and Availability of Echocardiographic Data } \\
\cline { 2 - 6 } & $\mathbf{0 . 5}$ & $\mathbf{1 . 0}$ & $\mathbf{2 . 0}$ & $\mathbf{3 . 0}$ & $\mathbf{4 . 0}$ \\
No. of patients contacted & $191 / 191$ & $168 / 169$ & $127 / 129$ & $84 / 84$ & $38 / 38$ \\
& $(100 \%)$ & $(99.4 \%)$ & $(98.4 \%)$ & $(100 \%)$ & $(100 \%)$ \\
Echo data & $191 / 191$ & $168 / 169$ & $127 / 129$ & $84 / 84$ & $38 / 38$ \\
& $(100 \%)$ & $(99.4 \%)$ & $(98.4 \%)$ & $(100 \%)$ & $(100 \%)$ \\
\hline
\end{tabular}

catheter lab. The patient underwent surgical removal of the migrated device, direct closure of the ASD, and valvuloplasty of the tricuspid valve with no residual neurological sequelae.

During the follow-up period ( $2.4 \pm 1.3$ years), no major complications (erosion, device embolization, infective endocarditis, thrombus formation, conduction abnormalities, or arrhythmias requiring pacemaker implantation ${ }^{19,20}$ ) were observed. No patient developed atrial flutter, fibrillation, or pericardial effusion (Tables 3,4).

A slight residual shunt was observed in 2 patients on the first follow-up examination 1 month after implantation. In the first patient, residual shunt was detected in association with aortic rim deficiency, and $<1 \mathrm{~mm}$ shunt flow remained. In the second patient, whose inferior vena cava rim was deficient, the residual shunt flow disappeared 2 months later.

No aortic regurgitation developed after device implantation. ${ }^{21}$ None of the patients experienced worsened associated mitral valve regurgitation or tricuspid valve regurgitation, and none developed left ventricular failure after device closure of the ASD. ${ }^{22,23}$

A total of 16 patients experienced new-onset migraines, which diminished within several months in most patients, but 10 patients received additional ticlopidine. Subsequently, all of them were able to stop the medication. Only one 7-year-old female patient had recurring migraines with aura during 18 months of treatment with clopidogrel and aspirin. The episodes of migraine with aura gradually decreased. There was close collaboration with a neurologist, and no pathological findings were recognized.

\section{Discussion}

Percutaneous closure is now widely accepted as the first choice for treating secundum ASD and patent foramen ovale (PFO). ${ }^{24}$ Intermediate- and long-term data have been reported with good results. The present single-institute report demonstrates that transcatheter closure of ASD using the ASO device is safe and effective. No cases of death, device embolization, erosions, thrombus formation, or stroke occurred during the follow-up period.

Erosions are considered to be caused by oversized devices and device embolization from undersized devices. There is no golden rule for determining the appropriate device size; this mainly depends on each institution's experience. ${ }^{25,26}$ Amin et $\mathrm{al}^{5}$ reviewed 28 patients, 14 of whom were in the United States, who developed hemodynamic compromise after ASO placement. Most erosions occurred at the dome of the atria, near the aortic root. Deficient aortic rims were recognized in $89 \%$ of cases, and defects were described as high ASD, suggesting a deficient superior rim. The device used to unstretch the ASD ratio was significantly larger in the hemodynamically compromised group when compared with the Food and Drug Administration (FDA) trial group. The incidence of device erosion in the United States was $0.1 \%$ among 9,000 ASO implantations. Patients with deficient aortic and/or superior rims were con- cluded to have a higher risk for device erosion. Avoiding intentional oversizing of the device by more than $2 \mathrm{~mm}$ of the balloon-stretched diameter of the defect was strongly recommended. In the current study, 67 patients $(32 \%)$ whose aortic rim was $<2 \mathrm{~mm}$ were included. All measurements were performed by the stop-flow method, and implanted devices were the same size as the sizing balloon's diameter. None of the patients developed erosion or pericardial effusion.

New-onset aortic regurgitation is an important complication in the long term. Shoen et al reported that aortic regurgitation occurred in $9 \%$ of patients with closed ASD and in $10 \%$ of patients with closed PFO among 240 consecutive patients who underwent percutaneous closure. ${ }^{21}$ The sprayed device of both disks over the aortic root could compress the non-coronary cusp after interatrial septum shrinkage developed because of endothelialization and tissue overgrowth on the device. When the balloon's stretched diameter was used to select the size of device, the increased device-to-defect ratio correlated with development of aortic regurgitation. Therefore, oversizing may be a contributing factor, although further long-term data are required to establish the relationship. As there were no cases of newly developed aortic regurgitation in the present study, the risk of developing aortic regurgitation might be avoided by measuring the defect with the stop-flow technique in order to select the minimum device size.

Arrhythmias during the procedure and in the immediate post-procedure period have been reported. ${ }^{20}$ An increased incidence of supraventricular premature beats after device placement among patients with increased $\mathrm{Qp}=\mathrm{Qs}$ and older age was observed. As there were no elderly patients in the present study, new-onset arrhythmia might not happen at all.

Chessa et $\mathrm{al}^{27}$ reported 11 of 417 patients who experienced arrhythmic problems: 6 patients with atrial fibrillation required electrical cardioversion, 2 with atrial fibrillation experienced spontaneous resolution, 2 with supraventricular tachycardia experienced spontaneous resolution, and 1 with complete atrioventricular block required removal of implanted device. Stretching of the interatrial septum by the central waist of the device was presumed to trigger the arrhythmic events. No new onset of arrhythmias or additional heart block was recognized during the follow-up period in the present study.

Krumsdorf et $\mathrm{al}^{28}$ reported the incidence of device thrombosis among 1,000 consecutive patients after closure of ASD or PFO. Thrombus formation occurred in 5 of 407 (1.2\%) patients with ASD and in 15 of 593 (2.5\%) patients with PFO. Two minor strokes caused by a left-sided mobile thrombus on a StarFLEX device, 1 minor stroke, and 1 transient ischemic attack occurred in 2 PFO-Star patients. Consequently, 3 patients had minor cerebrovascular accidents and 1 experienced a transient ischemic attack. No residual neurological sequelae were detected in this study. Because TEE was not conducted in all cases, minor thrombi might not have been detected. Follow-up after ASD closure remains necessary because of the risk of thrombus formation.

The mechanisms of new-onset migraine after ASD closure 
are unknown. ${ }^{29}$ Secretion of serotonin caused by activated platelets derived from the surface of the device has been hypothesized..$^{17}$ Stretching the atrial septum after device implantation, triggering the release of atrial natriuretic peptide, which is a vasoactive antagonist of vasopressin that aggravates migraine, is another explanation for migraine development. ${ }^{30}$ Further studies are mandatory to demonstrate the relationship between transcatheter ASD closure and new-onset migraines.

Rodés-Cabau et al reported that migraine headache attacks occurred in 13 of 185 patients (7\%) after ASD-PFO closure, with aura in 9 of 13 patients. ${ }^{29}$ In the current study, 16 patients (7.7\%) experienced migraine, with aura in 3 of them. The incidence of migraine was similar to the previous study. To control migraine headache attacks, ticlopidine was administered to 10 patients for $6-12$ months. In a 7 -year-old female patient, ticlopidine was required for 18 months, and her migraine headache attacks naturally diminished without any abnormal pathological findings. No adverse events have occurred in the 4 years since device implantation.

No cases of pulmonary vein obstruction, vena cava obstruction, or atrioventricular dysfunction were recognized during the follow-up period. ${ }^{7,8,10}$ However, continued long-term follow-up is essential for patients who have undergone transcatheter ASD closure because of the possibility of these occurring.

\section{Study Limitations}

The sample size in this study is a limiting factor. A larger sample may produce a larger number of adverse events. Our institution is a referral center; patients are referred from many parts of the country, so the sample is likely to have been representative of patients with ASD. Not all patients were available for follow-up after they had returned to their homes. However, the basic characteristics of patients unavailable for follow-up were similar to those of the group of patients with late followup data. Further research and follow-up are crucial to fully understanding this device and to improve the safety and efficacy of transcatheter ASD occlusion.

The level of highly sensitive cardiac troponin I in ASD patients is reported to be higher than in healthy children. ${ }^{31} \mathrm{In}$ present study, none of the patients had the serum level of highly sensitive cardiac troponin I measured.

\section{Conclusions}

Transcatheter ASD closure with the ASO was both safe and effective in the mid-term. The complications, mortality, and morbidity were low. Appropriate patient selection and the correct device size are mandatory for the success and safety of this procedure.

\section{References}

1. Du ZD, Hijazi ZM, Kleinman CS, Silverman NH, Larntz K; Amplatzer Investigators. Comparison between transcatheter and surgical closure of secundum atrial septal defect in children and adults: Results of a multicenter nonrandomized trial. $J$ Am Coll Cardiol 2002; 39: 1836-1844.

2. Butera G, De Rosa G, Chessa M, Rosti L, Negura DG, Luciane P, et al. Transcatheter closure of atrial septal defect in young children: Results and follow-up. J Am Coll Cardiol 2003; 42: 241-245.

3. Masura J, Gao W, Gavora P, Sun K, Zhou AQ, Jiang S, et al. Longterm outcome of transcatheter secundum-type atrial septal defect closure using Amplatzer septal occluders. J Am Coll Cardiol 2005; 45: $505-507$.

4. Oho S, Ishizawa A, Akagi T, Dodo H, Kato H. Transcatheter closure of atrial septal defects with the Amplatzer septal occluder: A Japanese clinical trial. Circ J 2002; 66: 791-794.

5. Amin Z, Hijazi ZM, Bass JL, Cheatham JP, Hellenbrand WE,
Kleinman CS. Erosion of Amplatzer septal occluder device after closure of secundum atrial septal defects review of registry of complications and recommendations to minimize future risk. Catheter Cardiovasc Interv 2004; 63: 496-502.

6. DiBardino DJ, McElhinney DB, Kaza AK, Mayer JE Jr. Analysis of the US Food and Drug Administration Manufacturer and User Facility Device Experience database for adverse events involving Amplatzer septal occluder devices and comparison with the Society of Thoracic Surgery congenital cardiac surgery database. J Thorac Cardiovasc Surg 2009; 137: 1334-1341.

7. Chun DS, Turrentine MW, Moustapha A, Hoyer MH. Development of aorta-to-right atrial fistula following closure of secundum atrial septal defect using the Amplatzer septal occluder. Catheter Cardiovasc Interv 2003; 58: 246-251.

8. Grayburn PA, Schwartz B, Anwar A, Hebeler RF Jr. Migration of an Amplatzer septal occluder device for closure of atrial septal defect into the ascending aorta with formation of an aorta-to-right atrial fistula. Am J Cardiol 2005; 96: 1607-1609.

9. Li W, Han W, Yu C, Zhang C, Tu Z, Wu S, et al. Severe mitral valve insufficiency after transcatheter atrial septal defect closure with the Amplatzer septal occluder: A device-related complication. J Card Surg 2009; 24: 672-674.

10. Moiduddin N, Cheatham JP, Hoffman TM, Phillips AB, Kovalchin JP. Amplatzer septal occluder associated with late pulmonary venous obstruction requiring surgical removal with acquired aorta to left atrial fistula. Am J Cardiol 2009; 103: 1039-1040.

11. Kitano M, Yazaki S, Sugiyama H, Yamada O. The influence of morphological changes in Amplatzer device on the atrial and aortic walls following transcatheter closure of atrial septal defects. J Interv Cardiol 2009; 22: 83-91.

12. Pepi M, Tamborini G, Bartorelli AL, Trabattoni D, Maltagliati A, De Vita $S$, et al. Usefulness of three-dimensional echocardiographic reconstruction of the Amplatzer septal occluder in patients undergoing atrial septal closure. Am J Cardiol 2004; 94: 1343-1347.

13. Carlson KM, Justino H, O'Brien RE, Dimas VV, Leonard GT Jr, Pignatelli RH, et al. Transcatheter atrial septal defect closure: Modified balloon sizing technique to avoid overstretching the defect and oversizing the Amplatzer septal occluder. Catheter Cardiovasc Interv 2005; 66: 390-396

14. Varma C, Benson LN, Silversides C, Yip J, Warr MR, Webb G, et al. Outcomes and alternative techniques for device closure of the large secundum atrial septal defect. Catheter Cardiovasc Interv 2004; 61: $131-139$.

15. Dalvi BV, Pinto RJ, Gupta A. New technique for device closure of large atrial septal defects. Catheter Cardiovasc Interv 2005; 64: $102-$ 107.

16. Masura J, Gavora P, Formanek A, Hijazi ZM. Transcatheter closure of secundum atrial septal defects using the new self-centering Amplatzer septal occluder: Initial human experience. Cathet Cardiovasc Diagn 1997; 42: 388-393.

17. Wilmshurst PT, Nightingale S, Walsh KP, Morrison WL. Clopidogrel reduces migraine with aura after transcatheter closure of persistent foramen ovale and atrial septal defects. Heart 2005; 91: 11731175 .

18. Tomita H, Hatakeyama K, Soda W, Kobayashi T. Efficacy of ticlopidine for preventing migraine after transcatheter closure of atrial septal defect with Amplatzer septal occluder: A case report. J Cardiol 2007; 49: 357-360.

19. Suda K, Raboisson MJ, Piette E, Dahdah NS, Miró J. Reversible atrioventricular block associated with closure of atrial septal defects using the Amplatzer device. J Am Coll Cardiol 2004; 43: $1677-$ 1682.

20. Hill SL, Berul CI, Patel HT, Rhodes J, Supran SE, Cao QL, et al. Early ECG abnormalities associated with transcatheter closure of atrial septal defects using the Amplatzer septal occluder. J Interv Card Electrophysiol 2000; 4: 469-474.

21. Schoen SP, Boscheri A, Lange SA, Braun MU, Fuhrmann J, Kappert $\mathrm{U}$, et al. Incidence of aortic valve regurgitation and outcome after percutaneous closure of atrial septal defects and patent foramen ovale. Heart 2008; 94: 844-847.

22. Ewert P, Berger F, Nagdyman N, Kretschmar O, Dittrich S, AbdulKhaliq $\mathrm{H}$, et al. Masked left ventricular restriction in elderly patients with atrial septal defects: A contraindication for closure? Catheter Cardiovasc Interv 2001; 52: 177-180.

23. Schubert S, Peters B, Abdul-Khaliq H, Nagdyman N, Lange PE, Ewert $\mathrm{P}$, et al. Left ventricular conditioning in the elderly patient to prevent congestive heart failure after transcatheter closure of atrial septal defect. Catheter Cardiovasc Interv 2005; 64: 333-337.

24. Zhang CJ, Huang YG, Huang XS, Huang T, Huang WH, Shen JJ. Transcatheter closure of patent foramen ovale in Chinese patients 
with paradoxical embolism: Immediate results and long-term followup. Circ J 2011; 75: 1867-1871.

25. Wang JK, Tsai SK, Lin SM, Chiu SN, Lin MT, Wu MH. Transcatheter closure of atrial septal defect without balloon sizing. Catheter Cardiovasc Interv 2008; 71: 214-221.

26. Hijazi Z, Wang Z, Cao Q, Koenig P, Waight D, Lang R. Transcatheter closure of atrial septal defects and patent foramen ovale under intracardiac echocardiographic guidance: Feasibility and comparison with transesophageal echocardiography. Catheter Cardiovasc Interv 2001; 52: 194-199.

27. Chessa M, Carminati M, Butera G, Bini RM, Drago M, Rosti L, et al. Early and late complications associated with transcatheter occlusion of secundum atrial septal defect. J Am Coll Cardiol 2002; 39: $1061-1065$.

28. Krumsdorf U, Ostermayer S, Billinger K, Trepels T, Zadan E, Horvath
$\mathrm{K}$, et al. Incidence and clinical course of thrombus formation on atrial septal defect and patient foramen ovale closure devices in 1,000 consecutive patients. J Am Coll Cardiol 2004; 43: 302-309.

29. Rodés-Cabau J, Molina C, Serrano-Munuera C, Casaldáliga J, AlvarezSabin J, Evangelista A, et al. Migraine with aura related to the percutaneous closure of an atrial septal defect. Catheter Cardiovasc Interv 2003; 60: 540-542.

30. Yankosvsky AE, Kuritzky A. Transformation into daily migraine with aura following transcutaneous atrial septal defect closure. Headache 2003; 43: 496-498.

31. Sugimoto M, Ota K, Kajihama A, Nakau K, Manabe H, Kajino H. Volume overload and pressure overload due to left-to-right shuntinduced myocardial injury: Evaluation using a highly sensitive cardiac Troponin-I assay in children with congenital heart disease. Circ J 2011; 75: 2213-2219. 